УДК 316.42

$10.17213 / 2075-2067-2021-4-17-22$

\title{
ГОТОВНОСТЬ И РЕСУРСНЫЕ ВОЗМОЖНОСТИ МОЛОДЕЖИ К УЧАСТИЮ \\ В МАССОВОЙ СПОРТИВНОЙ ДЕЯТЕЛЬНОСТИ
}

(C) 2021 г. А. А. Болозин

\section{Астраханский государственный университет, г. Астрахань, Россия}

Цель исследования состоит в том, чтобы рассмотреть возможности для занятий массовым спортом для российской молодежи в возрасте 21-30 лет. Речь идет, во-первых, об отношении молодежи как сочиальной группы к возможностям заниматься массовым спортом (иенности, потребности, интересы), и во-вторых, о соответствии между наличием устойчивых потребностей, отрефлексированных иченностей и выраженных интересов финансовым возможностям молодежи, необходимых для реализации вымеуказанных иенностей, потребностей и интересов в области массового спорта.

Методологической основой исследования является экспертный опрос, проведенный автором $(N=90)$ в трех субъектах федерации (Краснодарский край, Астраханская и Ростовская области) на основе авторской анкеты. В качестве экспертов выступили преподаватели физической культуры в вузах, тренеры спортивных школ, сотрудники профильных подразделений в системе государственного и муниципального управления по работе с молодежью.

Результаты исследования. Молодежь в возрасте 21-30 лет в основном обладает устойчивым отношением к массовому спорту как сочииальной иченности. В то же время проанализированные барьеры препятствуют молодежи стать участником спортивно-массовой деятельности, так как доступность к ней ограничена доминированием в этом сегменте платных услуг. В результате одна из наиболее активных социильных групп оказывается вовлеченной в массовый спорт в наименьшей степени, чем другие возрастные группь.

Перспективы дальнейших исследований автор видит в дальнейшей разработке теоретических, методологических и организачионно-технологических проблем повышения доступности молодежи массового спорта.

Ключевые слова: социальная иенность; спортивная инфраструктура; мотив; молодёжь; массовый спорт; доступность.

\section{READINESS AND RESOURCE CAPACITY \\ OF YOUNG PEOPLE TO PARTICIPATE IN MASS SPORTS ACTIVITIES}

\section{(C) 2021 A. A. Bolozin}

\section{Astrakhan State University, Astrakhan, Russia}

The purpose of the study is to consider the opportunities for mass sports for Russian youth aged 21-30 years. It is, first, about the attitude of young people as a social group to the opportunities to engage in mass sports (values, needs, interests) and, secondly, about the correspondence between the presence of stable needs, reflected values and expressed interests to the financial capabilities 
of young people necessary for the implementation of the above values, needs and interests in the field of mass sports.

The methodological basis of the study is an expert survey conducted by the author $(N=$ 90) in three federal subjects (Krasnodar Territory, Astrakhan and Rostov regions) based on the author's questionnaire. As experts, teachers of physical culture in universities, coaches of sports schools, employees of specialized departments in the system of state and municipal administration for work with youth were interviewed.

The results of the study. Young people aged 21-30 years generally have a stable attitude to mass sports as a social value. At the same time, the analyzed barriers prevent young people from becoming a participant in mass sports activities, since access to it is limited by the dominance of paid services in this segment. As a result, one of the most active social groups is less involved in mass sports than other age groups.

The author sees the prospects for further research in the further development of theoretical, methodological, organizational and technological problems of increasing the accessibility of mass sports for young people.

Key words: social value; sports infrastructure; motive; youth; mass sports; accessibility.

Введение. Для сохранения и укрепления здоровья молодежи немаловажное значение имеют такие факторы, как разумное соотношение труда и отдыха, правильное питание, закаливание организма и физические упражнения. Особое значение среди вышеуказанных факторов имеет физическая активность [3]. Общеизвестным является тот факт, что любая форма двигательной активности благоприятно сказывается на состоянии здоровья, способствует физическому развитию, предоставляет массу возможностей для активного отдыха и является одним из главных компонентов здорового образа жизни. Необходимый уровень двигательной активности может быть достигнут посредством регулярных физических упражнений, в числе которых приоритетное значение следует отдать массовому спорту.

Следует определиться с тем, есть ли у российской молодежи потребность и заинтересованность заниматься массовым спортом (ценностная направленность на спорт, находящаяся в области обычной социальной повседневности) и есть ли у российской молодежи финансовая возможность заниматься массовым спортом (если спорт существует в качестве платной услуги).

Анализ молодёжи возрастной когорты 21-30 лет как субъекта массового спорта. Вне всякого сомнения, необходимо учиты- вать тот факт, что «молодежь обладает различными социальными характеристиками, будучи дифференцированной по разнообразным критериям: возрастным, половым, поселенческим, этнокультурным, деятельностным. Сообразно этим критериям выделяют молодежь городскую и сельскую, учащуюся и работающую, имеющую собственный семейный статус или живущую в родительской семье и т.д.» $[4$, с. 265$]$.

Интерес к молодежи и ее социальной роли сегодня существенно возрос, изучение вопросов, связанных так или иначе с молодежной группой, актуализировалось и активизировалось не только в России, но и в мире. В сложившейся современной российской реальности особое внимание привлекают проблемы, касающиеся развития жизненных сил, физического и социального здоровья молодежи.

Молодежь представляет особой социально-демографическую, гетерогенную по социальным признакам группу, и особое место в ее «социализации» занимает массовый спорт.

Так, В.Н. Архангельский и А.Е. Иванова отмечают, что в молодом возрасте происходит дальнейшее активное развитие основных физических качеств человека, формируется телосложение и другие важнейшие физические и физиологические параметры [1]. Именно в период молодости закладываются основы образа жизни человека, его отношения к себе, своему здоровью. 
Далее необходимо рассмотреть все эти суждения в контексте отношения молодежи (возраст 21-30 лет) к массовому спорту. Следует начать с оценки степени вовлеченности молодых людей в спортивную деятельность. Согласно последнему в рамках заявленной проблемы изучению общественного мнения, проведенному ВЦИОМ 23-24 апреля 2017 года [2], массовым спортом (сюда также включается физическая культура) занимается $76 \%$ населения. Цифра достаточно весомая. Правда, при уточняющих вопросах, например, о регулярности занятий спортом, она снизилась до $23 \%$, что более чем в три раза ниже изначально полученной. Можно предположить, что первый показатель отражает скорее симпатии (наличие в той или иной степени осознаваемой потребности) по отношению к занятиям спортом, а второй — реальное количество людей, которые им занимаются. Кроме того, более половины из тех, кто указал, что занимается спортом, отметили, что делают это исключительно в домашних условиях. Наиболее интересный результат состоит в том, что количество ориентированной на спорт молодежи возраста 21-30 лет составляет наименьший процент по всем возрастным группам $37 \%$. Эта цифра может свидетельствовать об отсутствии интереса к спортивной деятельности, а может быть обусловлена и другими социальными обстоятельствами.

Согласно представлениям подавляющего большинства экспертов, спорт и физическая культура являются важнейшей социальной ценностью для молодежи в возрасте 21-30 лет. Более половины опрошенных (74 pecпондента) определили ее рейтинг в диапазоне от семи до десяти баллов, что в представленной классификации соответствует высокой и очень высокой иерархии значимостей.

Следовательно, очевидно определенное противоречие между невысокой интенсивностью реальной вовлеченности молодежи (21-30 лет) в массовую спортивную деятельность и высокими рейтинговыми показателями массового спорта в иерархии социальных ценностей молодых людей. Данное противоречие свидетельствует о том, что в социуме существуют определенные препятствия, мешающие реализации потребностей российской молодежи быть активным участником спортивно-массовой деятельности.
Следующий вопрос, который необходимо проанализировать, - мотивы, побуждающие молодежь заниматься спортивной деятельностью.

На первых трех местах оказались мотивы, отнесенные к первой группе: «ведение здорового образа жизни» (72 выбора); «улучшение фигуры» (63 выбора) и «увлечение определенным видом спорта, сформированное в детстве» (30 выборов). Мотивы второй группы вызвали заметно меньший интерес у экспертов с точки зрения признания их как присущих молодежи в возрасте 21-30 лет. Относительно частого избрания был удостоен только мотив «стремление к двигательной активности». Подобного рода итог свидетельствует о том, что, по мнению экспертов, молодежь обладает в достаточной степени устойчивыми ценностями, формирующими их интерес к массовому спорту не как на преходящую моду, развлечение от скуки, борьбу с самим собой, стремление избавиться от излишней энергии или занятия спортом за компанию, а как осмысленную внутреннюю потребность, поддерживаемую личной заинтересованностью в получении от участия в спортивной деятельности важных именно для отдельной личности результатов.

Далее необходимо оценить значимость для молодежи спорта как ценности.

Этот вопрос вызвал у экспертов разброс оценочных суждений, выраженных в тех баллах, которые можно считать рейтингом значимости спорта как социальной ценности.

Примерно пятая часть респондентовэкспертов сослалась на отсутствие интереса к массовому спорту у самой молодежи, но при этом весьма показательно, что больше половины всех опрошенных $(63,3 \%$ в процентном отношении к общему числу) в качестве ведущей причины указали на дефекты сложившейся спортивной инфраструктуры, где преобладают платные формы оказания услуг. Данный вывод представляется вполне обоснованным и справедливым. Действительно, если для детей, подростков и студентов созданы наиболее благоприятные условия для занятия массовым спортом, то сказать подобное о молодежи возрастной группы 21-30 лет нельзя. Именно на этот факт и обращают внимание эксперты. 
Оценка возможностей для занятий массовым спортом российской молодёжи в возрасте 21-30 лет. Можно предположить, что интерес к массовому спорту закладывается в раннем возрасте, в дошкольный и школьный периоды, студенческие годы, поэтому экспертам было предложено оценить потенциал высшего образования как фактора, формирующего ценности спортивного образа жизни. Этот вопрос был важен в контексте понимания ресурсных возможностей высшего образования для поддержания спортивных ценностей и интереса к спорту. Приведенные данные ВЦИОМ, согласно которым дети и подростки имеют высокий процент вовлечения в занятия спортом, свидетельствуют о том, что ресурсные возможности среднестатистической российской семьи на формирование здорового образа жизни достаточно высоки. Однако это не преуменьшает необходимость анализировать более поздний возраст, то есть студенческую молодежь, которая в вузах должна подтвердить свою готовность к активной вовлеченности в спорт, а вузы, соответственно, обеспечить для этого необходимые условия.

Полученные результаты свидетельствуют о том, что высшая школа, по мнению экспертов, обладает необходимым ресурсным потенциалом для поддержания общей социальной интенции на спорт как важнейшей ценности. В то же время почти пятая часть респондентов придерживается противоположного мнения, что можно истолковать как наличие возможных перспектив роста. Например, речь идет об улучшении материально-технической базы вузов, создании эффективной модели для развития студенческого спорта и т. д. Но в целом будем отталкиваться от полученного результата, который с указанными оговорками и пояснениями можно признать положительным.

Приступим к анализу соответствия между наличием устойчивых потребностей, рефлексированных ценностей и выраженных интересов финансовым возможностям молодежи, необходимым для реализации вышеуказанных ценностей, потребностей и интересов в области массового спорта.

Среди экспертов при ответе на данный вопрос обнаружился разброс мнений, причем оба выбора с ответом «да» и два варианта выбора с ответом «нет» в совокупности определяют паритет между собой по частоте оценочных суждений экспертов - «45 на 45», или в процентном эквиваленте в строгом соответствии с общеизвестным идиоматическим фразеологизмом - «50 на 50». Данная позиция должна примерно отражать реально сложившиеся финансовые возможности молодежи с учетом дифференциации как самой возрастной группы, так и дифференциации по предмету финансовой затратности разных видов спорта, которые могли держать в уме, давая соответствующую оценку, те или иные эксперты. И все же выбор третьего варианта ответа о том, что платные услуги слишком высоки и молодежь не готова тратить финансовые средства на занятия спортом, внушает известное беспокойство, так как если подобного рода оценка соответствует реальной действительности хотя бы отчасти, то это может быть важнейшим фактором эксклюзии большой группы молодежи в возрасте 21-30 лет из спортивно-массовой деятельности. Понятно, что это создает существенные ограничения для нормальной социализации молодежи, которая в анализируемом возрасте входит едва ли не в первую для молодых людей стадию сознательных выборов, когда давление агентов социализации резко снижается за счет того, что субъект социализации выбирает вектор социального развития самостоятельно, без акцентированного внешнего воздействия.

Для проверки этого предположения экспертам было предложено определить рейтинг готовности молодежи выбирать занятия массовым спортом в качестве платной услуги.

Практически половина всех экспертов оценили готовность молодежи (возраст 21-30 лет) посещать платные спортивные занятия как среднюю. При этом параметр «слабой готовности» удостоен на шесть выборов чаще (21 эксперт), чем параметр «высокой готовности» (15 экспертов).

Подобного рода ситуация актуализирует необходимость оценить то, насколько развита спортивная инфраструктура для предоставления возможности российской молодежи (21-30 лет) бесплатно заниматься массовым спортом. Даже если принять во внимание, что все эксперты никогда не будут довольны качеством спортивной инфраструктуры, 
количество отрицательных ответов все же внушает опасение. Действительно, 72 из 90 ответивших респондентов указали на недостаточность количества бесплатных спортивных объектов, необходимых для оптимальной вовлеченности молодежи анализируемого возраста в занятия массовым спортом. Из этого числа 30 респондентов прямо указали на то, что бесплатно заниматься спортом может только студенческая молодежь, a 42 эксперта высказали мнение о том, что требуется возведение новых элементов спортивной инфраструктуры для предоставления бесплатных спортивных услуг. Эти две позиции составляют мнение 80 \% всех принявших в опросе экспертов.

Поскольку исследование выявило потенциальную возможность эксклюзии молодежи (возраст 21-30 лет) из массово-спортивной деятельности и нехватку спортивных объектов, то все это может свидетельствовать о проблемах с обеспечением доступности занятиями массовым спортом.

Полученные результаты свидетельствуют о том, что увеличение потенциальных возможностей у российской молодежи (21-30 лет) для занятий спортом экспертами приоритетно связывается со строительством спортивных объектов и переориентацией интересов государства от приоритетного финансирования спорта высоких достижений к массовому спорту. Именно эти два варианта ответов, которые изначально связывались с основаниями, необходимыми для повышения финансовой доступности молодежи для занятий массовым спортом, были выбраны экспертами в качестве наиболее значимых. Улучшение других двух позиций было сочтено менее значимым.

Заключение. Молодежь в возрасте 21-30 лет является одной из наименее вовлеченных в массовый спорт возрастной группой. Однако результаты авторского экспертного опроса показали, что в основном молодежь имеет устойчивые побудительные мотивы для занятий массовым спортом, а это свидетельствует о прочности ее интересов в этой социальной сфере. Данная оценка находится в явном противоречии с реальной вовлеченностью молодежи анализируемого возраста в массовую спортивную деятельность. Ука- занное противоречие свидетельствует о том, что в социуме существуют институциональные ограничения, порождающие барьеры, которые мешают реализации потребностей российской молодежи в области массового спорта. В качестве одного из таких барьеров следует считать несоответствие между ростом платных услуг для занятий массовым спортом и финансовыми возможностями молодежи. В итоге российской молодежи в возрасте 21-30 лет присуща ориентированность на массовый спорт в качестве социальной ценности, она осознает потребность в занятиях массовым спортом и проявляет в этом заинтересованность, но реализации ее интересов препятствует отсутствие необходимых для этого финансовых возможностей, так как анализируемая возрастная группа в основном располагается в социальном сегменте, который должен самостоятельно обеспечивать для себя ресурсные возможности. Молодежь в возрасте 21-30 лет представляет собой социальную группу, которая оказывается за пределами существующих организационных, формализованных взаимодействий, установленных в социальном институте спорта для молодежи школьного и раннего студенческого возраста. Она поставлена в условия необходимости делать самостоятельный выбор относительно участия в массовой спортивной деятельности. Между тем на практике это приведет к еще большему уходу из системы сложившихся институциональных связей внутри социального института спорта. Таким образом, наблюдается серьезное отставание в становлении и развитии формальных норм, образующих институт массового спорта, от реальных социальных потребностей, способных определить его развития в социально желательном направлении.

\section{Литература}

1. Архангельский В. Н., Иванова А.Е. Стратегия демографического развития России. M., 2005. - C. 81.

2. Всероссийский опрос ВЦИОМ. 2324.04.2017 г. ( $\mathrm{N}=1200$ чел.). [Электронный pecypc]. - Режим доступа: https://wciom.ru/ index.php? $\mathrm{id}=236 \&$ uid $=116200$.

3. Кобяков Ю.П. Концепция норм двигательной активности человека // Теория 
и практика физической культуры. - 2013. №11. - С. 20-23.

4. Социологический словарь / Отв. ред. Г.В. Осипов, Л.Н. Москвичев. - М., 2008. C. 265.

\section{References}

1. Arhangel'skij V. N., Ivanova A.E. Strategija demograficheskogo razvitija Rossii [Strategy of demographic development of Russia]. Moscow, 2005. - P. 81.

2. Vserossijskij opros VCIOM. 2324.04.2017 g. ( $\mathrm{N}=1200$ chel.) [All-Russian poll of VTsIOM. 23-24.04.2017. ( $\mathrm{N}=1,200$ people)]. [Jelektronnyj resurs]. — URL: https:// wciom.ru/index.php?id=236\&uid=116200.

3. Kobjakov Ju. P. Koncepcija norm dvigatel'noj aktivnosti cheloveka [The concept of norms of human motor activity] // Teorija $i$ praktika fizicheskoj kul'tury [Theory and practice of physical culture]. — 2013. - №11. Pp. 20-23.

4. Sociologicheskij slovar' [Sociological dictionary] / In G. V. Osipov, L. N. Moskvichev (eds.). - Moscow, 2008. - P. 265.

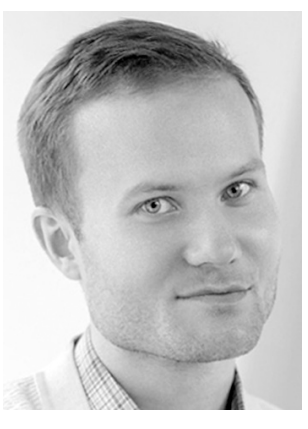

Болозин Андрей Александрович - старший преподаватель кафедры педагогики и непрерывного профессионального образования Астраханского государственного университета.

Bolozin Andrey Aleksandrovich - Senior Lecturer of the Department of Pedagogy and Continuing Professional Education of Astrakhan State University.

414004, г. Астрахань, ул. Баумана, 13, корп. 1, кв. 11

13 Bauman st., bld. 1, app. 11, 414004, Astrakhan, Russia

E-mail: andrew-bolozin@mail.ru 